\title{
Visual-Sensitive Epilepsies: Classification and Review
}

\author{
Shashi S. Seshia, Lionel Carmant
}

\begin{abstract}
Photosensitivity, photosensitive seizures, and photosensitive epilepsy are discussed. The International League against Epilepsy has suggested the term "visual-sensitive" replace "photosensitive". Visual-sensitive seizures may be more common than is realized. A classification for visual-sensitive epilepsies is presented. Chromosomal and DNA testing may help to refine the classification further. A standardized approach for neurophysiologic testing, such as that proposed by European experts, is recommended. These steps should promote evidenced-based management for this group of disorders.
\end{abstract}

RÉSUMÉ: Épilepsies photosensibles : classification et revue. Nous discutons de la photosensibilité, des crises photosensibles et de l'épilepsie photosensible. La International League against Epilepsy a suggéré que le terme «visual-sensitive» remplace le terme «photosensible». Les crises provoquées par la stimulation visuelle sont peutêtre plus fréquentes qu'on ne le croit. Nous présentons une classification de ces épilepsies. L'analyse des chromosomes et de l'ADN pourrait aider à raffiner davantage cette classification. Nous recommandons une approche standardisée de l'évaluation neurophysiologique, telle que proposée par des experts européens. Cette démarche devrait favoriser une thérapie factuelle dans ce type de maladie.

Can. J. Neurol. Sci. 2005; 32: 298-305

Epilepsy refers to recurrent (two or more) unprovoked seizures. Photosensitivity is defined as an abnormal electroencephalographic or clinical response to light. ${ }^{1}$ Seizures triggered by light stimuli have been known as photosensitive seizures. The International League against Epilepsy (ILAE) has proposed substituting the word "photosensitive" by the term "visual-sensitive".,2, Seizures and epileptic syndromes triggered by stimuli are designated as "reflex". Visual-sensitive are the most common of the reflex seizures, ${ }^{4-6}$ perhaps because there are many "seizure-triggering visual stimuli" in the environment. ${ }^{7,8}$

The electroencephalogram (EEG) incorporating intermittent photic stimulation (IPS) ${ }^{9}$ has become an essential tool for studying visual-sensitive seizures. The introduction, first of television (TV) and then of video games, created clinical interest in the subject to which many, primarily from Europe, have contributed. ${ }^{1,4,5,10-19}$ However, clinical and electroencephalographic methods have often varied between studies, confounding information on the subject. ${ }^{14}$

The "Pokemon epidemic"6 catalyzed new efforts to understand and address visual-sensitive seizures. Fortunately, several recent initiatives should promote uniformity. KasteleijnNolst Trenité et $\mathrm{al}^{20}$ have proposed a classification for visualsensitive epilepsy syndromes. Specific suggestions have also been made for standardizing methods for IPS in Europe. ${ }^{21,22}$ The ILAE is in the process of revising the classification for epileptic seizures and syndromes. ${ }^{2,3}$ Visual-sensitive seizures have not yet generated much interest in North America. For all these reasons, we felt that a review of the topic would be timely.

\section{VISUAL STIMULI THAT EVOKE VISUAL-SENSITIVE SEIZURES}

(1) Simple Flicker (Intermittent light stimulation)

Several common stimuli may provoke seizures. These include: flickering sunlight when traveling through avenues of trees or reflected off the sea or snow; lightning; headlights of cars; flickering light during movies, in amusement arcades, in discotheques, or from Christmas lights. , $^{1,5,7,8,11,14}$

From the Division of Pediatric Neurology, Department of Pediatrics (SSS), Royal University Hospital and University of Saskatchewan, Saskatoon, Saskatchewan; Division of Pediatric Neurology, Department of Pediatrics (LC), Hôpital Ste-Justine, Université de Montréal, Montréal, Quebec, Canada ReCEIVED June 3, 2004. ACCEPTED In FinAL FORM JANuARY 28, 2005 Reprint requests to: Shashi S. Seshia, Department of Pediatrics, Royal University Hospital and University of Saskatchewan, 103 Hospital Drive, Saskatoon, SK, Canada S7N 0W8 


\section{(2) Patterns}

The first case of pattern-sensitive seizures was described by Bickford et al. ${ }^{23}$ Since then, several investigators have discussed the subject. 4,5,17,23-27,27a Reported triggers include striped wallpaper, furnishings, clothing, Venetian blinds, picket fences, escalator treads, and air conditioner grills; ironing striped garments was considered particularly seizure evoking. ${ }^{17}$ Alternating black and white patterns or gratings oscillating in a direction orthogonal to their line orientation were highly epileptogenic; paroxysmal activity was very likely when the pattern changed direction 10 to 20 times per second, and patterns that differed in brightness were more epileptogenic than those that differed in color. ${ }^{17}$

\section{(3) Self-Induction}

Some children may self-induce seizures by (i) moving their hands in front of their eyes, (ii) eye-closure or (iii) staring at patterns. ${ }^{5,11,14,17,23,27,28}$ The case reported by Bickford et $\mathrm{al}^{23}$ would self-induce seizures by "actively gazing" at window screens or patterned fabrics on his father's tie, jacket, or coat. ${ }^{23,27}$ Self-induction, as a trigger may be overlooked. ${ }^{28}$

\section{(4) Television (TV) and Electronic screen (video) games}

(a) TV: Jeavons \& Harding ${ }^{11}$ credit Livingston as being the first to report "epileptic seizures" whilst watching TV. On the evening of December 16, 1997, around 700 children in Japan had seizures whilst watching a popular animated cartoon "Pokemon". Most of the seizures occurred during a scene in which red and blue frames alternated at $12 \mathrm{~Hz}$ for 4 seconds. ${ }^{29-31}$

(b) Video games ${ }^{32-36}$ Quirk et $\mathrm{al}^{33}$ estimated that in Great Britain, within the 7 to 19 years age group, the annual incidence of first seizures triggered by playing video games was $1.5 / 100,000 .^{33}$

(c) Mechanisms responsible for TV and video game provoked seizures. A number of factors are responsible:

\section{Innate}

An age-dependent genetic predisposition to visual-sensitive seizures from provoking stimuli is the most important cause..$^{8,14,19,37}$ However, since visual-sensitive seizures can occur in those with symptomatic epilepsies, acquired factors must also play a role. Withdrawal of anti-convulsant treatment, sleep deprivation, and fever in children may enhance the risk in the predisposed..$^{8,14,32,36,37}$

\section{Technical}

The TV screen is the most common stimulus for visualsensitive seizures whether it is used for viewing broadcast material, video play back or video games. ${ }^{14,29}$ Television sets generate flicker at the frequency of the mains current, even when the set is on without a displayed image. ${ }^{8,38}$ The frequency of the AC mains current, $50 \mathrm{~Hz}$ in Europe and $60 \mathrm{~Hz}$ in North America, is a key but not sole determinant of TV provoked seizures. ${ }^{8,11,14,37,38}$ Harding \& Jeavons ${ }^{14}$ found that $61 \%$ of their subjects had abnormalities to $50 \mathrm{~Hz}$ IPS compared to $22 \%$ at $60 \mathrm{~Hz}$ IPS, explaining the greater incidence of TV related seizures in Europe compared to North America. ${ }^{14,38}$ A $100 \mathrm{~Hz}$ screen reduces the risk of attacks. ${ }^{34,35}$

Pattern sensitivity may also be involved in TV related seizures $^{14,38,39}$ and is an important trigger for seizures provoked by video games. ${ }^{32-36}$ Some programs are more likely to evoke seizures than others; programs with steady maximal brightness (defined as the brightness of the brightest scene steadily present in a program for $>10$ seconds) exceeding 100 lux were found to be activating but those with $<50$ lux were considered relatively safe. ${ }^{36,40}$

Additionally, a number of other factors also make a contribution. ${ }^{14,32-37}$ These include: (i) high contrast between images, for example bright and dark frames alternating, (ii) speed of image change (image changes slower than three per second carry the lowest risk), (iii) color; red flicker and alternating red and blue color were found to be most provocative, and (iv) short distance from the screen, typically under $60 \mathrm{cms}$ or approaching the TV to adjust the set. Cognitive processes that occur during play may be important in provoking video game related seizures. . $^{82-37}$

\section{(5) Other visual stimuli and visual-sensitive seizures}

Fixation-off seizures (FOS) or EEG abnormalities are provoked by eliminating central vision and fixation for example when eyes are closed in a lighted room or when fixation is abolished. ${ }^{17,18}$

Scotosensitive seizures or EEG abnormalities occur in total darkness or when there is marked reduction of background light; thus, seizures often occur in darkness or when going into a dim lit room from bright sunlight. ${ }^{17,18}$

Both types may co-exist with sensitivity to IPS. ${ }^{18}$

\section{ELECTROPHYSIOLOGICAL DATA}

\section{(A) Normal response}

The normal EEG response to photic stimulation is characterized by the occurrence of visual evoked potentials timelocked to the flash frequency; sub-or supraharmonic responses

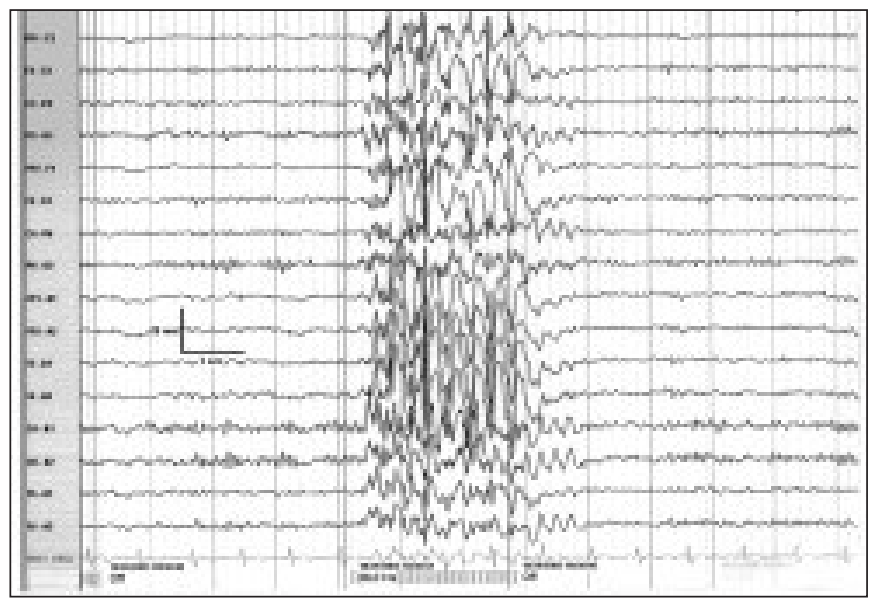

Figure 1: Generalized prolonged (self-sustaining) PPR. Relatively synchronous polyspike-slow wave paroxysm at $26 \mathrm{~Hz}$ stimulation (with eyes closed). No overt clinical correlate. 10-yr-old female with generalized seizures (not known to be visually sensitive). Low frequency filter: $1 \mathrm{~Hz}$; high frequency filter: $70 \mathrm{~Hz}$; notch: $60 \mathrm{~Hz}$; sensitivity: 20uv/mm; time base: $30 \mathrm{~mm} / \mathrm{sec}$. Machine settings are the same for Figures 2 \& 3 . 


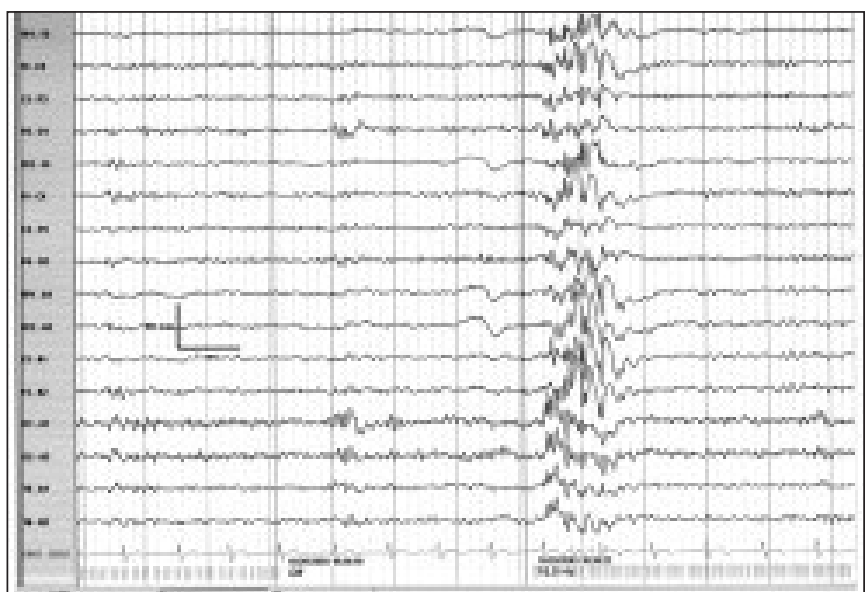

Figure 2: Generalized limited PPR. Relatively synchronous poly-spike slow wave paroxysm at $15 \mathrm{~Hz}$ stimulation (with eyes closed). No overt clinical correlate. Same patient as in Figure 1.

may occur. ${ }^{20}$

(B) EEG abnormalities in visual-sensitive patients

The literature is confounded by varying definitions of abnormal responses, and differences in all aspects of the recording technique. The terms, "photoconvulsive response" and "photoparoxysmal response" (PPR) have been used to describe the EEG abnormalities during IPS. Photoparoxysmal response is preferred because convulsive refers to a clinical phenomenon.

Several sub-types of responses to IPS have been described and their significance debated. ${ }^{20,41-44}$ Reilly \& Peters classified the response to IPS into one of four groups: ${ }^{41}$

(i) Prolonged. Epileptiform complexes or paroxysmal slow activity continuing beyond termination of the stimulus and occurring at a frequency or frequencies unrelated to the flash were called prolonged (Figure 1). If the response consisted of spikes or sharp and slow wave complexes, it was considered prolonged only if the last fast component clearly occurred more than $100 \mathrm{msec}$ after the last flash.

(ii) Self-limited. These responses were morphologically similar to that described for the prolonged class but ended either spontaneously during the flash (Figures $2 \& 3$ ) or ended at the same time as the flash,

(iii) Flash-dependent. Responses clearly time-locked to the flash rate that contained sharp or spike components were called flashdependent. Generally, they persisted as long as the flashes continued but some of them ceased spontaneously, and

(iv) Photomyoclonic. This response was generally limited to and always involved the anterior portion of the head. It consisted of muscle responses related to individual flashes.

Reilly and Peters ${ }^{41}$ found that some patients showed more than one type of response (Figures 1, 2, \& 3 are from the same EEG). They also observed that the duration of the response in relation to the flashes was related to its diagnostic value. Responses continuing beyond the flash train were highly associated with a convulsive disorder; self-limited and flashdependent responses were not as highly linked, whilst photomyoclonic responses were not related to epilepsy, an opinion shared by others. ${ }^{1,15}$ Several investigators have confirmed that generalized PPRs have a high association with epilepsy (70\%-90\%) and visual-sensitive seizures $(60 \%) .15,20,41-44$

In 1999, The International Federation of Clinical Neurophysiology defined PPR as: "abnormal response to intermittent photic stimulation characterized by spike-and-slow-wave and polyspike-and-slow-wave complexes. Responses are graded from occipital spikes time-locked to the flashes to generalized epileptiform discharges which may outlast the stimulus by a few seconds." " 45 The universal adoption of this definition should enhance consistency between studies on PPRs. Kasteleijn-Nolst Trenité DG et $\mathrm{al}^{20}$ have proposed a classification of EEG responses to IPS. The classification is similar to that described by Reilly and Peters ${ }^{41}$ :

(1) Photic following: (a) at flash rate or (b) at harmonics; we suggest the addition of (c) asymmetric

(2) Orbitofrontal photomyoclonus

(3) Posterior-stimulus-dependent response. Examples would include occipital spikes and the high-amplitude visual evoked potentials seen in neuronal ceroid lipofuscinosis.

(4) Posterior-stimulus-independent response

(a) Limited to stimulus train. The activity is confined to or maximal over the posterior region of the head and is independent of flash frequency. The response could be epileptiform or in the delta or theta ranges, or

(b) Self-sustaining. These outlast the stimulus train.

(5) Generalized PPR

(a) Limited to the stimulus train, or

(b) Self-sustaining and

(6) Activation of pre-existing epileptogenic area, an entity they

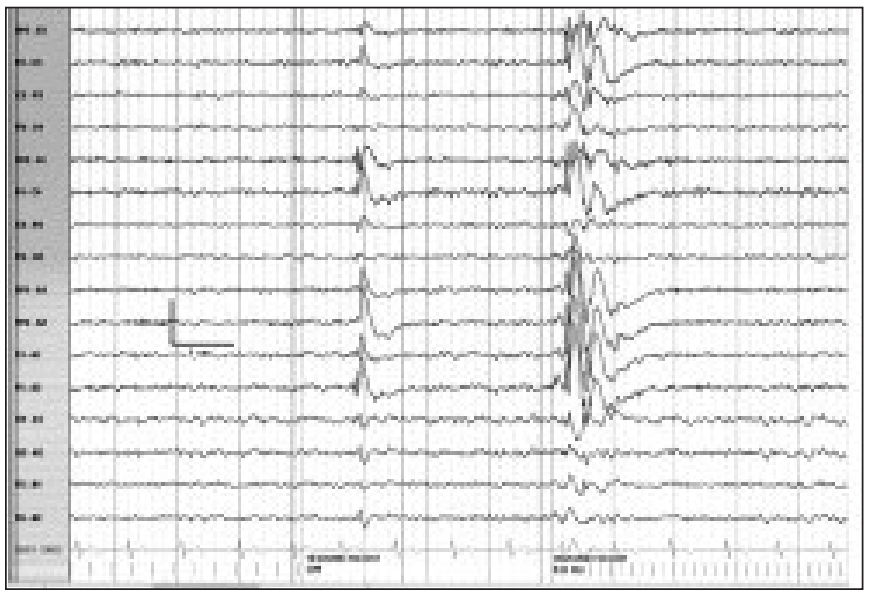

Figure 3: Generalized limited PPR. Relatively synchronous spike-slow wave paroxysm at $6 \mathrm{~Hz}$ stimulation (with eyes closed). No overt clinical correlate. Note the brief occurrence of a generalized fragment (or a frontally predominant) spike-slow wave paroxysm unrelated to photic stimulation. Same patient as in Figures 1 and 2. She also had similar abnormalities in the base-line record. 


\section{question}

We suggest the addition of,

(7) focal PPR, (a) limited to the stimulus train and (b) selfsustaining, to the list.

A generalized response to a wide range of frequencies may have greater clinical significance than one provoked by a single frequency of IPS. ${ }^{20}$ Responses may be attenuated by treatment. ${ }^{20}$

\section{(c) PPR in individuals without epilepsy}

Eeg-Olofsson et $\mathrm{al}^{46}$ found unequivocal PPRs in $8.3 \%$ of 743 normal children aged one year to 15 years, studied crosssectionally. Newmark and Penry ${ }^{1}$ concluded that from the information then available, that less than $2 \%$ of presumed nonepileptic subjects would have a PPR. The prevalence of abnormal EEG responses to IPS is estimated to range from $0.5 \%$ to $5 \% .^{20}$ Roy et $\mathrm{al}^{47}$ found that 14 of $1940(0.72 \%)$ entrants for training as pilots had a PPR on the EEG (one had a seizure during testing), compared to $3 \%$ of 1000 with known epilepsy.

\section{(d) The genetics of the PPR}

The PPR in those with idiopathic generalized visual-sensitive epilepsy and in their nonepileptic relatives is likely inherited on an autosomal dominant basis with the maximum age of penetrance being 5-20 years. ${ }^{19,48-50}$ However, visual-sensitivity in affected individuals may persist into adult life. ${ }^{14,51,52}$

\section{(e) Technical aspects}

Kasteleijn-Nolst Trenité et $\mathrm{al}^{21-22}$ described a consensus proposal from European experts, to standardize IPS testing, a proposal endorsed by Zifkin \& Kasteleijn-Nolst Trenité ${ }^{38}$ and Rubboli et al. ${ }^{53}$ We provide a brief summary of the proposal:

(i) The Grass PS22 photostimulator is considered the gold standard.

(ii) IPS should be performed three minutes after hyperventilation. Patient should be positioned $30 \mathrm{~cm}$ from the photic stimulator (nasion to lamp), with dim surrounding light. Flashes should be delivered in separate trains of ten seconds(s) for each frequency. The eyes should be open for the first $5 \mathrm{~s}$ and closed for the next $5 \mathrm{~s}$. An interval of $7 \mathrm{~s}$ should separate each train. The following frequencies should be used: 1,2,4,6,8,10,12,14,16,18, and $20 \mathrm{~Hz}$ and then 60,50,40,30, and $25 \mathrm{~Hz}$. The stimulator should be turned off if a generalized PPR is seen and testing stopped.

We are unaware of a similar initiative to test for pattern sensitivity or video game induced seizures, although a number of authors have outlined methods to test for pattern sensitivity. $4,5,11,14,17,24-26,54$ Since negative epileptic myoclonus can occur during photic stimulation, ${ }^{55}$ EMG leads should also be applied and (a period of) testing may have to be done in the sitting position. Otherwise, the clinical phenomenon may be missed.

The American EEG Society, ${ }^{56}$ the International Federation of Clinical Neurophysiology, ${ }^{57}$ and the task force of the Canadian Society of Clinical Neurophysiologists ${ }^{58}$ make only passing reference to IPS.

\section{The Proposed ILAE Classification ${ }^{3}$}

The ILAE has proposed a new diagnostic scheme for "people with epileptic seizures and epilepsy" 3 to replace the current classifications. ${ }^{59,60}$ Readers should consult the original reference as detailed discussion of the proposal is beyond the scope of this paper.

Axis 1: A description of ictal phenomenology.

Axis 2: Epileptic seizure type and precipitating factors for reflex seizures. The proposal incorporates "reflex seizures in generalized epilepsy syndromes" under "Generalized Seizures" and "reflex seizures in focal epilepsy syndromes" under "Focal Seizures". Within this axis, the ILAE has included "precipitating stimuli for reflex seizures", visual stimuli forming a subtype. The nature of the visual mechanism provoking the seizure should be specified in this axis and clinical and EEG data used to determine if the seizure is generalized or focal.

Axis 3: Syndromic diagnosis wherever possible. Reflex epilepsies, a category "still under discussion", are included among the syndromes.

Axis 4: Etiology. Presumably, in this axis, one can use the terms idiopathic, symptomatic, or probably symptomatic (formerly cryptogenic) to designate the cause.

Axis 5: This is meant to designate impairment from the epilepsy.

\section{A Proposed Classification for visual-Sensitive Seizures AND EPILEPSIES}

The ILAE proposed the use of the term "visual-sensitive" rather than "photosensitive" 2,3 but a definition is not provided. We would define visual-sensitive seizures as seizures provoked by visual stimuli or alteration of visual stimuli. Thus, visual stimuli would encompass (i) positive stimuli such as simple flicker, patterns, TV, video games, abrupt change of background lighting and fixation off, (ii) negative stimuli such as darkness and (iii) self-induced triggers/mechanisms.

The ILAE "anticipated" distinct "approaches to organization, categorization, and classification" of epilepsy syndromes for specific purposes. ${ }^{3}$ A classification for visual-sensitive epilepsies would comply with this philosophy. The following classification for the visual-sensitive epilepsies is a slight modification of that discussed by Kasteleijn-Nolst Trenite et $\mathrm{al}^{20}$ and Guerrini \& Genton. ${ }^{61}$ The classification is based on the frame-work formulated by the ILAE and can be easily revised as knowledge accrues.

\section{Seizure type}

Visual-sensitive seizures may be generalized (tonic-clonic, absence, myoclonic, etc.) or focal (secondarily generalized; motor; sensory with elementary visual or non-visual and experiential symptoms, etc). ${ }^{1,4,5,11,14-18,61}$ The triggers for such seizures may be overlooked without careful history taking; sensory seizures, absence seizures or seizures with "subtle" motor manifestations may not be reported by patients or recorded by observers. ${ }^{7,8,16,17,28,36,39}$

\section{Visual-sensitive Epilepsy Syndromes}

\section{A. Idiopathic \\ 1. Generalized}

1a. Visual-sensitive generalized epilepsy: Seizures are generalized, usually manifesting between five years and 19 years of age; females are more affected than males and there is a tendency for visual-sensitive seizures to decrease but not disappear after 25 years of age. The EEG shows a PPR and there 
is a family history of similar seizures and EEG responses.

1b. Pattern-sensitive epilepsy: Brinciotti et $\mathrm{al}^{62}$ described two unrelated families with individuals whose seizures were provoked by environmental visual patterns. Although those sensitive to patterns are also sensitive to flicker stimuli, some patients with pattern-sensitive epilepsy do not show any abnormality to IPS. ${ }^{14}$ Further observations are necessary to determine if idiopathic pattern-sensitive epilepsy is distinct from the better-described idiopathic visual-sensitive epilepsy in which flicker is the principal trigger. Overlap cases may well occur.

1c. Other idiopathic generalized visual-sensitive epilepsies: In this group, seizures occur spontaneously but are also triggered by visual stimuli; PPRs may be seen on the EEG; examples in this category would include:

(i) Juvenile myoclonic epilepsy (JME)

(ii) Childhood absence epilepsy (CAE)

(iii) Juvenile absence epilepsy (JAE)

(iv) Epilepsy with myoclonic astatic seizures

(v) Epilepsy with myoclonic absences, and

(vi) Benign myclonic epilepsy in infancy

In the study of Wolf \& Goosses, ${ }^{63} 18 \%$ of those with CAE, $7.5 \%$ of those with JAE and $30.5 \%$ of those with JME were found to be visual-sensitive to IPS.

2. Focal. A number of authors have discussed cases that would fall into this group ${ }^{17,18,64-67}$ Examples in this category include:

(i) (Idiopathic visual-sensitive) Occipital lobe epilepsy

(ii) Early and late onset childhood occipital epilepsy and

(iii) Photogenic partial seizures

FOS and scotosensitive seizures often occur in childhood occipital epilepsy. ${ }^{17,18}$ Taylor et $\mathrm{al}^{68}$ have drawn attention to the phenotypic overlap between JME and idiopathic photosensitive (visual-sensitive) occipital lobe epilepsy suggesting "shared genetic determinants" between these two epilepsy syndromes, one regarded as generalized, and the other as focal.

\section{B. Symptomatic}

\section{Generalized}

Symptomatic or probably symptomatic (formerly, cryptogenic) generalized visual-sensitive epilepsies: In this group, visual-sensitive seizures constitute only one aspect of the symptomatology and there is an underlying cause. Examples within this class include:

(i) Progressive myoclonus/myoclonic epilepsies (example: ceroid lipofuscinosis, Lafora disease and myoclonic epilepsy with ragged red fibers MERRF); Ohtsuka et $\mathrm{al}^{69}$ described two siblings with MERRF who had an abnormal response to IPS but did not have clinical visual-sensitive seizures and

(ii) Chromosomal abnormality. Example: Refractory myoclonic visual-sensitive (photosensitive) epilepsy with complex rearrangement of chromosome $2 .^{70}$

\section{Focal.}

Symptomatic focal visual-sensitive epilepsies:

Examples within this category include:

(i) Occipital lobe epilepsies ${ }^{71-72}$

(ii) Temporal lobe epilepsy with focal PPR $\mathrm{P}^{73-75}$ and (iii) Frontal lobe epilepsy (partial complex seizures) with ring 20 chromosome anomaly. ${ }^{76}$ Seizures in this child often occurred whilst playing video games.

\section{Visual-sensitive epilepsies not classifiable as either idiopathic or symptomatic}

Dravet Syndrome (severe myoclonic epilepsy in infancy) would be an example in this category. Infants with this condition have been reported to be sensitive to constant bright illumination and may self-induce seizures. ${ }^{77}$ Prospective studies are needed to determine if some visual stimuli are relatively specific for particular epilepsy syndromes.

Reading epilepsy is classified separately from the visualsensitive epilepsies. ${ }^{3,4,78}$

\section{EVIDENCE FOR FOCAL OR REGIONAL ORIGIN OF VISUAL- SENSITIVE SEIZURES}

Clinical, ${ }^{15-18,20,37,38,61,64,65}$ EEG, ${ }^{12,13,15}$ functional MRI, ${ }^{79}$ magnetoencephalographic, ${ }^{80}$ physiologic $\mathrm{c}^{81,82}$ and experimental data $^{1,83,84}$ strongly support a focal or regional (occipital) origin for visual-sensitive seizures. Hennessy \& Binnie ${ }^{65}$ suggested that all visual-sensitive seizures by definition might be partial with rapid secondary generalization, originating in the visual cortex. Wilkins et $\mathrm{al}^{82}$ share this opinion and suggest that in "visually sensitive individuals," cortical neurons in the occipital cortex have characteristics that contribute to seizure precipitation. The corpus callosum plays an important role in propagation between hemispheres. ${ }^{85}$

\section{NEUROTRANSMITTER AND MOLECULAR GENETIC MECHANISMS}

Disturbances in dopaminergic ${ }^{86}$ and serotonergic ${ }^{87}$ mechanisms have been proposed. Cossette et $\mathrm{al}^{88}$ reported a mutation in the GABRA1 gene on chromosome 5 in a family with JME. ${ }^{88}$ All affected members had generalized polyspike and waves with visual sensitivity. However, a correlation between this mutation and visual sensitivity is unlikely as individual IV-2 who had a PPR without clinical seizures did not have the mutation. Chromosome 2 apparently harbors genes involved in voltagegated ion channels and neurotransmitters, genes which may be involved in visual-sensitivity. ${ }^{70}$ Stephani et al $^{50}$ have discussed candidate genes with promising links to the PPR. Recently, Pinto et $\mathrm{a}^{89}$ described possible linkage for the PPR to chromosomal regions $7 \mathrm{q} 32$ and $16 \mathrm{p} 13$.

\section{Management}

We have summarized the data from several sources. ${ }^{1,5,11,14,16-}$ $18,24,25,32,54,90$ In predisposed individuals, the risk of seizures may be minimized by covering one eye before exposure to provoking stimuli.

(1) Minimizing the risk of video game/TV induced seizures

(i) The viewing distance should be at least four times the diagonal screen measurement. Dr. Takahashi (personal communication) suggests a viewing distance of at least three meters.

(ii) The room should be well lighted.

(iii) Prolonged play (example > one hour per session) should be avoided.

(iv) The subject should not play when sleep deprived or febrile. 
(v) Binnie et $\mathrm{al}^{32}$ suggest that people with known epilepsy or with a family history of photosensitivity should not play electronic games until an EEG examination including a period of patterned photic stimulation has been carried out.

(vi) Those known to be visually sensitive should not play electronic games when they are alone.

(vii) The subject should not approach the TV screen to adjust the set.

(viii) From a technical viewpoint, screens with 100-Hz., games of $<50$ lux and the use of special optical filters or glasses may minimize the risk of visual-sensitive seizures. ${ }^{91,92}$

\section{(2) Minimizing the risk of seizures provoked by other visual} stimuli.

(i) Photosensitive subjects should wear polarized glasses in the sun.

(ii) Seizures that occur exclusively in darkness (example at night) may be minimized with the use of a night light. ${ }^{18}$

(3) Those who have both unprovoked and visual-sensitive seizures should be treated with an anticonvulsant as should those who have frequent visual-sensitive seizures because of poor compliance to preventative measures. Valproic acid is considered the first choice in this situation but the benzodiazepines, clobazam, ethosuximide, lamotrigine, levetiracetam, and topiramate are apparently also effective. ${ }^{16,90}$ Covanis et al ${ }^{90}$ list lamotrigine as their second choice. To the best of our knowledge, these opinions are not been based on randomized controlled trials. Prospective studies are needed to determine if lamotrigine would be a better choice to valproic acid for females of childbearing age with visual-sensitive epilepsy. De Bittencourt ${ }^{37}$ suggested that drugs like phenytoin and carbamazepine might provoke visual-sensitive seizures.

\section{(4) Minimizing epileptogenic potential of electronic games and} TV Programs

Standards to minimize visual-sensitive seizures from televised programs have been adopted in some countries. ${ }^{29,93,94}$ Similar policies have been suggested for video material, electronic screen games, and the Internet. ${ }^{94}$

\section{ACKNOWLEDGEMENTS}

Shashi S. Seshia is grateful for a clinical traineeship grant from the Region Advisory Committee 2 of the Royal College of Physicians and Surgeons of Canada. Many of the concepts in this paper were summarized in Lumina (Volume 21, 2003). We thank Drs. Prasanna Jayakar, Noel Lowry, Manikum Moodley, Molly Seshia, Jerome Yager, and the Staff of the EEG Laboratory at the Royal University Hospital, Saskatoon for reviewing the draft and to the EEG Laboratory, University Hospital, London, Ontario for permission to use Figures $1,2, \& 3$.

\section{REFERENCES}

1. Newmark ME, Penry JK. Photosensitvity and Epilepsy: a Review. New York: Raven Press, 1979:xii; 3-6, 145-181.

2. Engel Jr. J. A proposed diagnostic scheme for people with epileptic seizures and with epilepsy: Report of the ILAE task force on classification and terminology. Epilepsia 2001; 42: 796-803.

3. International League against Epilepsy (ILAE) task force on classification and terminology. A proposed diagnostic scheme for people with epileptic seizures and with epilepsy: report of the
ILAE task force on classification and terminology. ILAE Web site:2005.http://www.ilaeepilepsy.org/visitors/centre/ctf/index .cfm. Last Accessed January 10, 2005.

4. Gastaut H, Tassinari CA. Triggering mechanisms in epilepsy. The electroclinical point of view. Epilepsia 1966; 7:85-138.

5. Bickford RG, Klass DW. Sensory precipitation and reflex mechanisms. In: Jasper HH, Ward Jr. AA, Pope A, (Eds). Basic Mechanisms Of The Epilepsies. 1st Ed. Boston: Little, Brown \& Company, 1969: 543-573.

6. Kasteleijn-Nolst Trenité DGA, Guerrini R, Genton P. Introduction. Epilepsia 2004; 45(Suppl 1) :1.

7. Kasteleijn-Nolst Trenité DGA, van der Beld G, Heynderickx I, Groen P. Visual stimuli in daily life. Epilepsia 2004; 45 (Suppl 1): 2-6.

8. Zifkin BG, Inoue Y. Visual reflex seizures induced by complex visual stimuli. Epilepsia 2004; 45 (Suppl 1): 27-29.

9. Walter WG, Dovey VJ, Shipton H. Analysis of the electrical response of the human cortex to photic stimulation. Nature 1946; 158: 540-541.

10. Andermann F. Self-induced television epilepsy. Epilepsia 1971; 12: 269-275.

11. Jeavons PM., Harding GFA. Photosensitive epilepsy. Clinics in Developmental Medicine no.56. London: Spastics International Medical Publications, 1975.

12. Wilkins AJ, Binnie CD, Darby CE. Interhemispheric differences in photosensitive epilepsy. I. Pattern sensitivity thresholds. Electroencephalogr Clin Neurophysiol 1981; 52: 461-468.

13. Binnie CD, Wilkins AJ, De Korte RA. Interhemispheric differences in photosensitive epilepsy. II Intermittent photic stimulation. Electroencephalogr Clin Neurophysiol 1981; 52: 469-472.

14. Harding GFA, Jeavons PM. Photosensitive epilepsy. Clinics in Developmental Medicine no.133. London Mac Keith Press, 1994.

15. Kasteleijn-Nolst Trenité DG. Photosensitivity in epilepsy: electrophysiological and clinical correlates. Acta Neurol Scand 1989; 80 ( Suppl 125): 1-149.

16. Kasteleijn-Nolst Trenité DG. Reflex seizures induced by intermittent light stimulation. In: Zifkin BG, Andermann F, Beaumanoir A, Rowan AJ, (Eds). Reflex Epilepsies and Reflex Seizures. Advances in Neurology Vol 75. Philadelphia: Lippincott-Raven Publishers, 1998: 99-121.

17. Binnie CD, Wilkins AJ. Visually induced seizures not caused by flicker (intermittent light stimulation). In: Zifkin BG, Andermann F, Beaumanoir A, Rowan AJ, (Eds). Reflex Epilepsies and Reflex Seizures. Advances in Neurology Vol 75. Philadelphia: Lippincott-Raven Publishers, 1998: 123-138.

18. Panayiotopoulos CP. Fixation-off, scotosensitive, and other visualrelated epilepsies. In: Zifkin BG, Andermann F, Beaumanoir A, Rowan AJ, (Eds). Reflex Epilepsies and Reflex Seizures. Advances in Neurology Vol 75. Philadelphia: Lippincott-Raven Publishers, 1998: 139-157.

19. Doose H, Gerken H, Hien-Volpel KF, Volzke E. Genetics of photosensitive epilepsy. Neuropediatrie 1969;1:56-73.

20. Kasteleijn-Nolst Trenité DG, Guerrini R, Binnie CD, Genton P. Visual sensitivity and epilepsy: A proposed termininology and classification for clinical and EEG phenomenology. Epilepsia 2001; 42: 692-701.

21. Kasteleijn-Nolst Trenité DGA, Binnie CD, Harding GFA, Wilkins A. Photic Stimulation: Standardization of screening methods. Epilepsia 1999; 40 (Suppl 4): 75-79.

22. Kasteleijn-Nolst Trenité DGA, Binnie CD, Harding GFA, et al. Medical technology assessment: photic stimulation: standardization of screening methods. Neurophysiol Clin 1999; 29: 318-324.

23. Bickford RG, Daly D, Keith HM. Convulsive effects of light stimulation in children. Amer J Dis Child 1953; 86: 170-183.

24. Chatrian GE, Lettich E, Miller LH, Green JR. Pattern-sensitive epilepsy. Part I. An electrographic study of its mechanisms. Epilepsia 1970; 11: 125-149.

25. Chatrian GE, Lettich E, Miller LH, Green JR, Kupfer C. Patternsensitive epilepsy. Part 2. Clinical changes, tests of responsiveness and motor output, alterations of evoked potentials and therapeutic measures. Epilepsia 1970; 11: 151-162. 
26. Wilkins AJ, Andermann F, Ives J. Stripes, complex cells and seizures. Brain 1975; 98: 365-380.

27. Radhakrishnan K, Klass DW. Half a century of visual patternsensitive epilepsy. Mayo Clin Proc 2004; 79: 269-270.

27a. Radhakrishnan K, St. Louis EK, Johnson JA et al. Pattern-sensitive epilepsy: Electroclinical characteristics, natural history, and delineation of the epileptic syndrome. Epilepsia 2005; 46:48-58. (An informative analyses of 73 patients).

28. Matricardi M, Brinciotti M, Trasatti G, Porro G. Self-induced pattern-sensitive epilepsy in childhood. Acta Paediatr Scand 1990; 79: 237-240.

29. Harding GFA, Harding PF. Televised material and photosensitive epilepsy. Epilepsia 1999; 40 (Suppl 4): 65-74.

30. Takada H, Aso K, Watanabe K, et al. Epileptic seizures induced by animated cartoon, "Pocket Monster." Epilepsia 1999; 40: 9971002.

31. Takahashi T, Kamijo K, Takaki Y, Yamazaki T. Suppressive efficacies by adaptive temporal filtering system on photoparoxysmal response elicited by flickering pattern stimulation. Epilepsia 2002; 43: 530-534,

32. Binnie CD, Harding GFA, Richens A, Wilkins A. Video games and epileptic seizures-a consensus statement. Seizure 1994; 3: 245246.

33. Quirk JA, Fish DR, Smith SJM, et al. First seizures associated with playing electronic screen games: a community- based study in Great Britain. Ann Neurol 1995; 37: 733-737.

34. Badinand-Hubert N, Bureau M, Hirsch E, et al. Epilepsies and video games: results of a multicentric study. Electroencephalogr clin Neurophysiol 1998; 107: 422-427.

35. Kasteleijn-Nolst Trenité DG, Martins da Silva A, Ricci S, et al. Video-games are exciting: a European study of video gameinduced seizures and epilepsy. Epileptic Disord 2002; 4: 121-128.

36. Bureau M, Hirsch E, Vigevano F. Epilepsy and Videogames. Epilepsia 2004; 45(Suppl 1): 24-26.

37. de Bittencourt PRM. Photosensitivity: the magnitude of the problem. Epilepsia 2004; 45(Suppl 1): 30-34.

38. Zifkin BG, Kasteleijn-Nolst Trenité D. Reflex epilepsy and reflex seizures of the visual system: a clinical review. Epileptic Disord 2000; 2: 129-136.

39. Stefansson SB, Darby CE, Wilkins AJ et al. Television epilepsy and pattern sensitivity. BMJ 1977; 2: 88-90.

40. Ricci S, Vigevano F. The effect of video-game software in videogame Epilepsy. Epilepsia 1999; 40(Suppl 4): 31-37.

41. Reilly EL, Peters JF. Relationship of some varieties of electroencephalographic photosensitivity to clinical convulsive disorders. Neurology 1973; 23: 1050-1057.

42. Jayakar P, Chiappa KH. Clinical correlations of photoparoxysmal responses. Electroencephalogr Clin Neurophysiol 1990; 75: 251254.

43. Puglia JF, Brenner RP, Soso MJ. Relationship between prolonged and self-limited photoparoxysmal responses and seizure incidence: study and review. J Clin Neurophysiol 1992; 9: 137144.

44. Nagarajan L, Kulkarni A, Palumbo-Clark L, et al. Photoparoxysmal responses in children: their characteristics and clinical correlates. Pediatric Neurol 2003; 29: 222-226.

45. Noachtar S, Binnie C, Ebersole J, et al. A glossary of terms most commonly used by clinical electroencephalographers and proposal for the report form for the EEG findings. In: Deuschl G, Eisen A. (Eds). Recommendations for the Practice of Clinical Neurophysiology: Guidelines of the International Federation of Clinical Neurophysiology (2nd revised and enlarged edition). Electroenceph Clin Neurophysiol 1999; (Suppl 52): 21-41.

46. Eeg-Olofsson O, Petersen I, Sellden U. The development of the electroencephalogram in normal children from the age of 1 through 15 years. Paroxysmal activity. Neuropadiatrie 1971; 2: 375-404.

47. Roy AK, Pinheiro L, Rajesh SV. Prevalence of photosensitivity-an Indian experience. Neurology (India) 2003; 51: 241-243.

48. Doose H, Waltz S. Photosensitivity-genetics and clinical significance. Neuropediatrics 1993; 24: 249-255.
49. Waltz S, Stephani U. Inheritance of photosensitivity. Neuropediatrics 2000; 31: 82-85.

50. Stephani U, Tauer U, Koeleman B et al. Genetics of photosensitivity (photoparoxysmal response): a review. Epilepsia 2004; 45 (Suppl 1): $19-23$.

51. Harding GF, Edson A, Jeavons PM. Persistence of photosensitivity. Epilepsia 1997; 38: 663-669.

52. Anyanwu EC, Ehiri JE, Jones J. Photosensitive epilepsy beyond adolescence: is freedom from photosensitivity age-dependent? Int J Adolesc Med Health 2003; 15: 125-132.

53. Rubboli G, Parra J, Seri S, Takahashi T, Thomas P. EEG diagnostic procedures and special investigations in the assessment of photosensitivity. Epilepsia 2004; 45(Suppl 1): 35-39.

54. Zifkin B, Andermann F. Visual-sensitive epilepsies. ILAE web site 2005. http://www.ilae-epilepsy.org/visitors/centre/ctf/index.cfm. Last accessed January 10, 2005.

55. Gambardella A, Aguglia U, Oliveri RL, et al. Photic-induced epileptic negative myoclonus: a case-report. Epilepsia 1996; 37 : 492-494.

56. American Electroencephalographic Society. Guidelines in electroencephalography, evoked potentials, and poly-somnography. J Clin Neurophysiol 1994; 11: 2-9.

57. Nuwer MR, Comi G, Emerson R et al. IFCN standards for digital recording of clinical EEG In: Deuschl G, Eisen A, (Eds). Recommendations for the Practice of Clinical Neurophysiology: Guidelines of the International Federation of Clinical Neurophysiology. 2nd revised and enlarged edition. Electroenceph Clin Neurophysiol 1999; (suppl 52): 11-14.

58. Task force of the Canadian Society of Clinical Neurophysiologists. Minimal Standards for Electroencephalography in Canada. 2002; 29: 216-220.

59. Commission on Classification and Terminology of the International League against Epilepsy. Proposal for revised clinical and electroencephalographic classification of epileptic seizures. Epilepsia 1981; 22:489-501.

60. Commission on classification and terminology of the International League against Epilepsy. Proposal for revised classification of epilepsies and epileptic syndromes. Epilepsia 1989; 30: 389-399.

61. Guerrini R, Genton P. Epileptic syndromes and visually induced seizures. Epilepsia 2004; 45(Suppl 1): 14-18.

62. Brinciotti M, Trasatti A, Pelliccia A, Matricardi M. Pattern-sensitive epilepsy: genetic aspects in two families. Epilepsia 1992; 33: 8892.

63. Wolf P, Goosses R. Relation of photosensitivity to epileptic syndromes. J Neurol Neurosurg Psych 1986; 49: 1386-1391.

64. Ricci S, Vigevano F. Occipital seizures provoked by intermittent light stimulation: ictal and interictal findings. J Clin Neurophysiol 1993; 10: 197-209.

65. Hennessy MJ, Binnie CD. Photogenic partial seizures. Epilepsia 2000; 41: 59-64.

66. Yalcin AD, Kaymaz A, Forta H. Reflex occipital lobe epilepsy. Seizure 2000; 9: 436-441.

67. Taylor I, Scheffer IE, Berkovic SF. Occipital lobe epilepsies: identification of specific and newly recognized syndromes. Brain 2003; 126: 753-769.

68. Taylor I, Marini C, Johnson MR et al. Juvenile myoclonic epilepsy and idiopathic photosensitive occipital lobe epilepsy: is there overlap? Brain 2004; 127: 1878-1886.

69. Ohtsuka Y, Amano R, Oka E, Ohtahara S. Myoclonus epilepsy with ragged-red fibers: a clinical and electrophysiologic follow-up study on two sibling cases. J Child Neurol 1993; 8: 366-372.

70. Van Esch H, Syrrou M, Lagae L. Refractory photosensitive epilepsy associated with a complex rearrangement of chromosome 2 . Neuropediatrics 2002; 33: 320-323.

71. Aso K, Watanbe $\mathrm{K}$, Negoro $\mathrm{T}$, et al.Visual seizures in children. Epilepsy Res 1987; 1: 246-253.

72. Guerrini R, Bonanni P, Parmeggiani L et al. Induction of partial seizures by visual stimulation. In: Zifkin BG, Andermann F, Beaumanoir A, Rowan AJ, (Eds). Reflex Epilepsies and Reflex Seizures. Advances in Neurology Vol 75. Philadelphia: Lippincott-Raven Publishers, 1998: 159-178. 
73. Benbadis SR, Gerson WA, Harvey JH, Luders HO. Photosensitive temporal lobe epilepsy. Neurology 1996; 46: 1540-1542.

74. Isnard J, Guenot M, Fischer C, et al. A stereoencephalographic (SEEG) study of light-induced mesiotemporal epileptic seizures. Epilepsia 1998; 39: 1098-1103.

75. Fiore LA, Valente K, Gronich G, Ono CR, Buchpiguel CA. Mesial temporal lobe epilepsy with focal photoparoxysmal response. Epileptic Disord 2003; 5: 39-43.

76. Takahashi Y, Shigematsu H, Kubota H, et al. Nonphotosensitive video game-induced partial seizures. Epilepsia 1995; 36: 837841.

77. Oguni H, Hiyashi K, Awaya Y, Fukuyama Y, Osawa M. Severe myoclonic epilepsy in infants-a review based on the Tokyo Women's Medical University series of 84 cases. Brain Dev 2001; 23: 736-748.

78. Zifkin B, Andermann F. Reading epilepsy. ILAE Web site.2005. http://www.ilae-epilepsy.org/visitors/centre/ctf/index.cfm. Last accessed January 10, 2005.

79. Chiappa KH, Hill RA, Hellinger-Huang F, et al. Photosensitive epilepsy studied by functional magnetic resonance imaging and magnetic resonance spectroscopy. Epilepsia 1999; 40(Suppl 4): 3-7.

80. Ricci GB, Chapman RM, Erne SM, et al. Neuromagnetic topography of photoconvulsive response in man. Electroencephalogr Clin Neurophysiol 1990; 75:1-12.

81. Harding GFA, Fylan F. Two visual mechanisms of photosensitivity. Epilepsia 1999; 40: 1446-1451.

82. Wilkins AJ, Bonanni P, Porciatti V, Guerrini R. Physiology of Human Photosensitivity. Epilepsia 2004; 45(Suppl 1): 7-13.

83. Naquet RG, Valin A. Experimental models of reflex epilepsy. In: Zifkin BG, Andermann F, Beaumanoir A, Rowan AJ, (Eds). Reflex Epilepsies and Reflex Seizures. Advances in Neurology Vol 75. Philadelphia: Lippincott-Raven Publishers, 1998: 15-28.

84. Menini C, Silva-Barrat C. The photosensitive epilepsy of the baboon. In: Zifkin BG, Andermann F, Beaumanoir A, Rowan AJ, eds. Reflex Epilepsies and reflex seizures. Advances in Neurology Vol 75. Philadelphia: Lippincott-Raven Publishers, 1998: 29-47.

85. Naquet R, Wada JA. Role of the corpus callosum in photosensitive seizures of epileptic baboon Papio papio. Adv Neurol 1992; 57 : 579-587.

86. Quesney LF, Andermann F, Gloor P. Dopaminergic mechanisms in generalized photosensitive epilepsy. Neurology 1981; 12: 15421544.
87. Anyanwu E, Harding GF, Edson A. The involvement of serotonin (5-hydroxytryptamine) in photosensitive epilepsy. J Basic Clinic Physiol Pharmacol 1994; 5: 179-206.

88. Cossette P, Liu L, Brisebois K, et al. Mutation of GABRA1 in an autosomal dominant form of juvenile myoclonic epilepsy. Nat Genet 2002; 31: 184-189.

89. Pinto D, Westland B, de Haan GJ, et al. Genome-wide linkage scan of epilepsy-related photoparoxysmal electroencephalographic response: evidence for linkage on chromosomes $7 \mathrm{q} 32$ and $16 \mathrm{p} 13$. Hum Mol Genet 2005; 14: 171-178.

90. Covanis A, Stodieck SRG, Wilkins AJ. Treatment of photosensitivity. Epilepsia 2004; 45(Suppl 1): 40-45.

91. Takahashi Y, Sato T, Goto K, et al. Optical filters inhibiting television-induced photosensitive seizures. Neurology 2001; 57: 1767-1773.

92. Kepecs MR, Boro A, Haut S, Kepecs G, Moshe SL. A novel nonpharmacologic treatment for photosensitive epilepsy: a report of three patients tested with blue cross-polarized glasses. Epilepsia 2004; 45: 1158-1162.

93. Takahashi Y, Fujiwara T. Effectiveness of broadcasting guidelines for photosensitive seizure prevention. Neurology 2004; 62: 990993.

94. Harding GFA, Takahashi T, Regulations: what next? Epilepsia 2004; 45(Suppl 1): 46-48.

\section{NOTE TO READERS}

This reference was added for readers regarding the updated definition of Epilepsy.

Fisher RS, van Emde Boas W, Blume W et al. Epileptic seizures and epilepsy: Definitions proposed by the International League Against Epilepsy (ILAE) and the International Bureau for Epilepsy (IBE). Epilepsia 2005; 46:470-472. (The definition of epilepsy has just been altered). 